\title{
UN RELATO EN EL HIELO: DE LA POSTERGACIÓN EDITORIAL COMO ESTRATEGIA LITERARIA EN UN RELATO DE RICARDO PIGLIA
}

\author{
Mirko Olivati \\ Universidad de Murcia \\ mirko.olivati@gmail.com
}

\begin{abstract}
Resumen: El objetivo de este artículo es ofrecer un análisis del cuento "Un pez en el hielo" de Ricardo Piglia, publicado en la nueva edición de 2006 de la colección de cuentos La invasión, primer libro del escritor argentino en 1967. En las próximas páginas se considerarán las elecciones editoriales de Piglia, los textos teóricos sobre el cuento que el autor publicó entre la primera y la segunda edición de La invasión, las indicaciones que dejó en su obra autoficcional Los diarios de Emilio Renzi y la relación artística que Piglia quiso instaurar con el escritor italiano Cesare Pavese escribiendo este cuento, para mostrar cómo un relato aparentemente lineal puede adquirir un espesor y una profundidad particulares gracias a las estrategias literarias del escritor, evidenciando posibilidades aún no exploradas para el género literario del relato.
\end{abstract}

Palabras clave: Ricardo Piglia, reescritura, La invasión, “Un pez en el hielo”, Cesare Pavese.

\section{A SHORT STORY ON ICE: ON THE EDITORIAL POSTPONEMENT AS LITERARY STRATEGY IN ONE OF RICARDO PIGLIA'S SHORT STORIES}

\begin{abstract}
The aim of this paper is to offer an analysis of Ricardo Piglia's short story "Un pez en el hielo", included in the new 2006 edition of the short story collection La invasion, the first book published by the Argentinean writer in 1967. In the next pages we will consider Piglia's editorial choices, the theoretical texts on the short story that the author published between the first and second edition of La invasion, the indications he left in his auto-fictional work The diaries of Emilio Renzi, and the artistic relationship that Piglia wanted to establish with the Italian writer Cesare Pavese through this short story, in order to show how an apparently linear story can acquire a particular thickness and depth thanks to the writer's literary strategies, bringing to light possibilities not yet explored for the literary genre of the short story.
\end{abstract}

Keywords: Ricardo Piglia, rewriting, La invasión, "Un pez en el hielo”, Cesare Pavese.

DOI: https://doi.org/10.24029/lejana.2019.12.361

Recibido: el 13 de mayo de 2019

Aceptado: el 28 de junio de 2019

Publicado: el 30 de octubre de 2019. 
Pasaba la tarde sentado ante el espejo para hacerme compañia... Cesare Pavese: El oficio de vivir

\section{1.}

A lo largo de su trayectoria literaria, el escritor argentino Ricardo Piglia ha abarcado diversos géneros y ha trabajado sus formas innovándolas y experimentando con la hibridez entre ellas, mezclando en sus obras ficción y crítica, desarrollando estrategias editoriales y literarias con un alto nivel de conciencia estética. Aunque su primera obra publicada se caracteriza por cierto realismo y linealidad, ya desde ahí es posible darse cuenta de varias peculiaridades, tanto temáticas y formales como editoriales y de estrategia literaria a largo término que ha ido luego desplegando en el curso de su carrera.

El libro con el cual Piglia hace su debut como escritor es una colección de relatos breves que se edita en La Habana, Cuba, con el título Jaulario, en 1967, tras haber recibido una mención de honor por Casa de las Américas. Aunque comenzar el trayecto literario con un libro de cuentos parezca ser la elección más normal para los escritores latinoamericanos del siglo XX, y en particular los argentinos (muy probablemente gracias al espacio abierto por Borges, a la necesidad de los escritores del Cono Sur, y particularmente por los argentinos, de enfrentarse con su obra) la historia del comienzo literario de Piglia tiene rasgos muy peculiares. En efecto se podría hablar de dos comienzos o de un comienzo doble al mundo literario, por cuanto a la misma colección de cuentos se edita pocos meses después en Buenos Aires, por la editorial Jorge Álvarez, bajo otro título, La invasión, y con algunas modificaciones estructurales (como el ordenamiento diferente de los textos y la presencia de "Mi amigo", un cuento que se había publicado anteriormente, en 1964, en la antología Cuentistas premiados, como ganador del premio organizado por la revista El Escarabajo de Oro) y formales (como la presencia de variantes lexicales y otros cambios en el orden de varios párrafos en diferentes cuentos). ${ }^{1}$

Así los cuentos de Jaulario son diez, mientras que en La invasión se encuentran once; la primera colección empieza con "Tierna es la noche" y el último relato es "Las actas del juicio", pero la versión argentina cambia el lugar de varios cuentos entre los cuales, justamente, el primero y el último, "Tarde de amor", se convierte en el exordio de la obra, y "Tierna es la noche" viene a ser el cuento conclusivo, además, se cambia de título a "Desde el terraplén" y a "En el calabozo", que se transforman respectivamente en "En el terraplén" y "La invasión". Las variantes formales, en particular el desplazamiento de varios párrafos en algunos de los cuentos, llegan a ser muy significativas, produciendo cambios en los planos temporales, en el ritmo de la prosa y hasta en la significación de los relatos mismos.

Cada uno de esos cambios es testimonio de lúcidas reflexiones del joven autor sobre el cuento breve como género, y certifica que la elección de introducirse en el mundo literario justamente de esa forma no ha sido meramente oportunista, sino que esconde y desvela una inquietud estética profunda, además de la voluntad fuerte de crear un espacio propio en el campo literario argentino, entonces ocupado plenamente por la figura ya mítica de Borges y

\footnotetext{
${ }^{1}$ La diferencia entre los dos libros de cuentos son detalladamente analizadas por Daniel Mesa Gancedo en su ensayo "Una propuesta de lectura en el origen de la obra de Ricardo Piglia", en el cual relaciona dichos cambios con las inquietudes estéticas del escritor frente al comienzo y al final de un relato (2006: 163-226).
} 
por la admiración hacia las experimentaciones de Cortázar. Voluntad detectable claramente en el cambio del título de la colección, como se intuye leyendo la entrada del lunes 21 de noviembre de 1966 del primer tomo de Los diarios de Emilio Renzi: "Decido como título del volumen Jaulario (me molesta que suene al Bestiario de Cortázar y al Crepusculario de Neruda, pero no encuentro un nombre mejor y no quiero usar el título de un cuento para todo el libro" (Piglia, 2015: 268); a la hora de editar el libro en Buenos Aires, Piglia decide dejar al lado el título "cortazariano" prefiriendo el nuevo, La invasión.

Este doble debut de 1967, representado por Jaulario y La invasión, además de las inquietudes estéticas que conlleva, se complica ulteriormente en 2006, cuando Piglia, después de casi 40 años, decide dar a la luz una edición nueva de la colección. La operación no es nada pasiva, y habría que considerarla a la luz de las declaraciones del autor en el prólogo al libro, pero también de lo que el mismo Piglia ha publicado entre esas fechas, en particular sus reflexiones teórico-críticas sobre el cuento, contenidas en libros como Crítica y ficción y Formas breves, y después de 2006, sobre todo por el gran giro que produce en toda la obra pigliana la publicación, entre 2015 y 2018, de Los diarios de Emilio Renzi.

La diferencia más evidente en la nueva edición de La invasión consiste en la presencia de otros cinco cuentos y de un prólogo, con el cual Piglia justifica la decisión de reescribir este libro y asimismo nos ofrece algunas informaciones sobre los cuentos que no estaban en la edición de 1967:

[...] he agregado cinco relatos a la serie inicial. "Desagravio" (1963), "En noviembre" (1965) y "El pianista" (1968) se publicaron inicialmente en revistas literarias de Buenos Aires en esos años. Los revisé y reescribí tratando de ser fiel a la idea original y los incluyo ahora en la sección que reproduce los cuentos de La invasión porque forman parte de la misma serie. [...] Los dos relatos más extensos — que abren y cierran el volumen— son inéditos. "El joyero" fue escrito en 1969 y "Un pez en el hielo" a principio de 1970. Los dos textos pasaron por diversas versiones y múltiples reescrituras. Me pareció pertinente incluirlos en el libro porque fueron escritos con la misma concepción de la literatura que el resto de los relatos (2006a: 1314).

Así, la secuencia de los catorce relatos que siguen al prólogo del autor se ve enmarcada por "El joyero" y "Un pez en el hielo", únicos dos cuentos totalmente inéditos a la hora de la publicación del libro. Al mismo tiempo, los cuentos que ya estaban presentes en la edición de 1967 hallan una disposición nueva en la cual se mantienen significativamente como primero y último cuento, respectivamente "Tarde de amor" y "Tierna es la noche", justamente son los que sufren más modificaciones formales en la versión nueva. El primero en particular se presenta como el único que ha sido reescrito por completo, como explica Piglia en el prólogo, añadiendo que "no me convencía la primera versión y poco tiempo después de publicar el libro volví a escribirlo manteniendo la situación pero cambiando los personajes. Por supuesto la misma historia con otros protagonistas es otra historia (y sin embargo en un sentido es también la misma)" (2006a: 12-13).

Con las variantes de "Tierna es la noche" y de los otros cuentos, Piglia se propone especialmente quitar párrafos y reducir la extensión de los cuentos, en el intento de seguir fielmente la teoría del iceberg de Hemingway, citado explícitamente en el prólogo, y de trabajar sobre otra inquietud que le acompaña al escritor argentino a lo largo de todo su recorrido literario y que él mismo explica en una entrevista contenida en Crítica y ficción: "la 
posibilidad de concentrar un argumento es algo que me interesa especialmente: hasta dónde se puede reducir una historia, es decir, hasta dónde se la puede reducir para que siga funcionando" (2001: 186).

En efecto, tanto por lo que concierne a los cuentos ya presentes en la edición de 1967 como a los cinco añadidos en 2006 y escritos en esa misma época, el influjo del primer Hemingway, del Hemingway cuentista, es bastante evidente y, una vez más, confirmado por el mismo Piglia, quien en el prólogo a la edición de 2016 de En nuestro tiempo, colección de cuentos del americano, recuerda su primer contacto con la lectura de sus relatos:

[...] en una librería de libros usados en la terminal de ómnibus de Mar del Plata, en una galería encristalada, sobre una mesa de saldos, encontré, en 1959, un ejemplar de In Our Time y esa tarde volví a casa y lo leí de un tirón, me tiré en un sillón de lona, con las piernas apoyadas en una silla, y empecé a leerlo y seguí y seguí. A medida que avanzaba en la lectura la luz cambiaba y declinaba. Terminé casi a oscuras, al fin de la tarde, alumbrado por el reflejo pálido de la luz de la calle que entraba por los visillos de la ventana. No me había movido, no había querido levantarme para encender la lámpara porque temía quebrar el sortilegio de esa prosa. Concluí el libro en plena oscuridad. Cuando por fin me levanté y prendí la luz ya era otro. Ahora me doy cuenta de que la forma del recuerdo, la luz que declina hasta que cae la noche, está influida por la prosa de Hemingway, por su capacidad para captar el sentimiento con leves matices y cambios de tono. La gravitación de esa lectura está presente, nítida, en los cuentos de La invasión, mi primer libro. Como tantos escritores, yo había buscado liberarme del falso estilo literario que ensombrecía la literatura argentina. Mi experiencia con este libro me abrió las puertas de la experimentación narrativa (2016: 11).

El hecho de que Piglia, al llegar al límite extremo de su carrera literaria (el prólogo a Hemingway fue escrito cuatro meses antes de su muerte), vuelve a hablar de su primer libro de cuentos, no debe sorprender, sino que habría que relacionarlo con la estrategia que el escritor ha desarrollado constantemente en su obra, y que consiste en volver continuamente a leer, corregir, escribir los viejos textos y cambiarlos de contexto desplegando lo que el mismo Piglia llama "lectura utópica":

escribir es sobre todo corregir, no creo que se pueda separar una cosa de otra. De todos modos cuando el texto está terminado hay un trabajo de corrección que es bastante singular. Uno hace el esfuerzo de ponerse en lugar de una especie de lector perfecto, capaz de detectar todas las fallas y los nudos del texto y trata de leer lo que ha escrito como si fuera de otro. En este sentido la corrección es una lectura utópica y tan interminable como la escritura misma. (2001: 54).

En esta estrategia se inscribe la reedición de 2006 de La invasión, colección de cuentos releídos y corregidos por Piglia, que pone de manifiesto cómo "su máquina de narrar trama nuevos significados desde lo ya escrito y publicado cambiando de lugar los textos en otros contextos históricos" (Romero, 2010: 1).

Lo que pasa es que Piglia se ha aplicado en complicar conscientemente esta situación en el tiempo por medio de varias tácticas, formales y editoriales, cuyo punto cumbre ha sido la publicación de Los diarios de Emilio Renzi, libro en el cual el escritor, hablando de los mecanismos de su obra previa, empuja el lector a emprender nuevas lecturas de la misma y a preguntarse cómo su significado cambia tras el conocimiento de esas nuevas informaciones ofrecidas por el mismo autor. De esta forma, la modalidad de cada texto se vuelve más significativa y hasta la ausencia de un texto en un libro adquiere su peculiar importancia; como nota agudamente Teresa Orecchia Havas en su ensayo, 
no es fácil entonces pensar lo editado y lo inédito contraponiéndolos como opuestos; son más bien versiones de una topografía cambiante, de un corpus siempre en movimiento y transformación, de una concepción de la literatura que acerca el escribir al componer (musicalmente), el crear al interpretar (una partitura secreta), el publicar al "editar" (o sea, cortar y montar) o aun al reeditar, burlando la "superstición" del texto original o definitivo (2019a: 8).

En este sentido, el desdoblamiento del primer libro de Piglia entre 1967 y 2006 se caracteriza como caso emblemático, justamente por la obstinación del autor en volver a reelaborar sus viejos cuentos, como él mismo explica en la conclusión del prólogo de la edición de 2006 de La invasión:

[...] reescribir viejas historias tratando de que sigan iguales a lo que fueron es una benévola utopía literaria, más benévola en todo caso que la esperanza de inventar siempre algo nuevo. Una ilusión suplementaria podría hacernos pensar qua al reescribir los relatos que concebimos en el pasado volvemos a ser lo que fuimos en el momento de escribirlos. (2006a: 14).

Otro elemento significativo que esa colección de cuentos pone de relieve es la cuestión de la postergación de la publicación de textos ya escritos. Como se ha visto, es el mismo Piglia quien establece, en el prólogo a La invasión, los años de composición de los cuentos que no habían hallado espacio en la precedente edición, y tanto los que habían sido ya publicados en revistas como los dos inéditos habrían sido escritos antes de 1971.

En los siguientes apartados me centraré sobre uno de esos cuentos, "Un pez en el hielo", que se caracteriza justamente por su ausencia en la obra editada por Piglia hasta 2006 y que, tras la publicación de Los diarios de Emilio Renzi, además de varias otras intervenciones críticas y teóricas del escritor argentino, ha ido adquiriendo un espesor especial, lo que permite reflexionar sobre esta estrategia desarrollada por Piglia.

\section{2.}

"Un pez en el hielo" es el cuento que cierra la edición de 2006 de La invasión y es sin duda el más literario de la colección, pues se centra en la reconstrucción que el protagonista, un joven Emilio Renzi quiere hacer de los últimos días de vida del escritor italiano Cesare Pavese.

Sin duda se trata de un relato que tenía mucha importancia para Piglia, quien lo coloca como último cuento de La invasión (sabemos qué peculiar importancia tienen las conclusiones en las reflexiones literarias de Piglia) y lo reedita en 2014 en Antología personal. Además, Los diarios de Emilio Renzi ofrecen una gran cantidad de referencias a la ideación y construcción de una "historia de Pavese" (Piglia, 2015: 142). En fin, "Un pez en el hielo" es el relato en que el alter ego de Ricardo Piglia, Emilio Renzi, comienza a trasformarse en el escritor imaginario que aparecerá en Respiración artificial y muchas otras de sus obras, el escritor adolescente que se enfrenta al mundo y que se funda sobre modelos bien claros para el autor: "Emilio Renzi es una especie de Stephen Dedalus errante, un Quentin Compson que vive en Almagro, quiero decir, es el joven artista, el esteta que mira el mundo con desprecio" (Piglia 2001: 93).

La estructura del cuento es tripartita: en la primera parte se entrelazan entre sí la historia de la pesquisa sobre el diario de Cesare Pavese que Renzi está emprendiendo en Turín $\mathrm{y}$, por otra parte, la historia de su relación con Inés, la mujer que Renzi quiere olvidar y que 
aparece en la ciudad italiana, turbando fuertemente al joven. Es curiosa la manera de tratar las dos historias en relación al tema del doble: la aparición inesperada de Inés al principio del cuento desencadena en el protagonista unas agitadas reflexiones sobre los dobles que podríamos tener en otros continentes:

[...] sabía lo que estaba pasando pero no lograba calmarse. Encontraba conocidos por todos lados [...]. Empezó a creer que teníamos un doble en el otro continente, el mundo era un espejo, y todo estaba duplicado pero fuera de lugar. Una mujer igual a Inés con el hombre de pelo blanco era demasiada coincidencia. Los dos dobles iguales en el otro lado del mundo. No podía ser, desvariaba. Atacado por un impulso mimético, veía todo repetido, construía réplicas (Piglia, 2006a: 176-177).

Al mismo tiempo Renzi, en el momento en que pone su atención en el trabajo sobre Pavese, actúa y reflexiona como si fuera un doble del escritor turinés:

[...] abrió el mapa del Piamonte y volvió a ubicar Santo Stefano Belbo, el pueblo estaba a unos noventa kilómetros, en la región de las Langhe. Belbo era el nombre del río que atravesaba el pueblo. Pavese había nacido ahí en 1908, se mató a los cuarenta y dos años. Emilio hizo cuentas. "Me quedan quince años... no, quince no, dieciséis", calculó. "Muchísimo tiempo". Empezó a tomar notas. Estaba trabajando sobre el Diario de Pavese. Solo quien lleva un diario puede leer el diario que escriben otros. Tachó la última frase y escribió: Solo quien lleva un diario puede entender el diario que llevan otros. Leyó la frase y la tachó otra vez y al lado escribió: Solo quien escribe un diario puede entender el diario que escriben otros. Pavese había escrito uno de los mejores diarios que se habían escrito nunca... porque se había matado (Piglia, 2006a: 177).

El continuo desdoblarse de personajes, situaciones (la de Renzi, abandonado por su mujer como siempre lo fue Pavese, es una réplica de la situación de ese último) y objetos (el diario donde Renzi apunta sus reflexiones mezcladas con citas del diario de Pavese), enfatizan el mecanismo de construcción del relato, que está estructurado de manera bastante transparente en la teoría expuesta por Piglia en "Tesis sobre el cuento", un breve ensayo publicado en el volumen Formas breves en 1999, donde el escritor define la naturaleza doble de la forma cuento y afirma, como primera tesis, que "un cuento siempre cuenta dos historias" (2006b: 105).

La segunda sección detalla el viaje en tren del protagonista, decidido por profundizar el misterio del suicidio de Pavese, hacia Santo Stefano Belbo, el pueblo natal del escritor; durante el viaje desarrolla varias reflexiones literarias, desencadenadas por la lectura de su diario: Renzi ve, detrás de una lectura paralela de Pavese y Kafka, un vínculo secreto entre la literatura, las mujeres y la muerte, cree que allí está la solución del enigma acerca de los últimos días de Pavese y de su suicidio: "Renzi estaba releyendo esas viejas notas que ahora le parecían íntimamente ligadas a su hipótesis sobre el final de Pavese. La literatura, las mujeres y la muerte" (2006a: 185).

En la última parte del cuento irrumpe un personaje extraño, un coleccionista polaco (¿un doble del Tardewski de Respiración artificial?) que le muestra a Renzi un objeto misterioso, una copia de Black Angel, la última película en que actuó Constance Dowling, el último gran amor fracasado de Pavese. La copia del polaco tiene una particularidad, una diferencia que la convierte en un objeto único: se trata de la versión no comercializada, sin cortes, de la película, e incluye una escena más respecto a la versión oficial; supuestamente esta copia perteneciera a Pavese que, los días antes del suicidio, probablemente, contempló la 
proyección de la amada que lo había abandonado. En la breve escena es invierno y se ve a la mujer que deja una pecera en el balcón, luego regresa a su casa y al final de la secuencia la policía irrumpe, después de dos días, en la casa: "la ventana está cerrada, el pez afuera en la pecera congelada. (Un pez inmóvil en un bloque de hielo). Y la muchacha muerta en el piso" (Piglia, 2006a: 187).

En el desenlace del cuento, que tiene un final abierto o un no-final, Renzi, tras haberse despedido del polaco y salido de la exposición, encuentra a Inés y rechaza su invitación a seguir el viaje con ella y el hombre que la acompaña.

Como se puede percibir en el resumen del relato, "Un pez en el hielo", aunque parezca un texto bastante lineal, es uno extremamente complejo que condensa en sí prácticamente todos los intereses e inquietudes tanto formales como temáticas que Piglia seguirá desarrollando en su carrera literaria; como bien subraya en su análisis del cuento Ana Gallego Cuiñas, "Piglia pone de manifiesto en este texto los principales vectores que atraviesan sus ficciones: la motivación de la narración (la pérdida de la mujer), el vacío de significación que deja un misterio (el tema del doble) y/o enigma, el desplazamiento del sentido (la ficción paranoica) y la forma del diario (Archivo)" (2008: 4).

Todos estos elementos están puestos tan de manifiesto en el cuento que no me parece atrevido suponer que Piglia haya querido esperar crear y asegurarse su espacio en el campo literario argentino antes de entregar a sus lectores ese "manual para leer las ideas nucleares" (Gallego Cuiñas, 2008: 5) de su obra, persiguiendo una estrategia que él mismo ha explicado en una entrevista hablando de Borges como escritor-crítico: "Esto es lo que llamo lectura estratégica: un crítico que constituye un espacio que permita descifrar de manera pertinente lo que escribe. Todo el trabajo de Borges como antólogo, como editor de colecciones y como prologuista está encaminado en esa dirección” (Piglia, 2006a: 155).

\section{3.}

Es un hecho que Piglia, tanto en los años en que supuestamente estaba escribiendo "Un pez en el hielo" cuanto más tarde, cuando el cuento estaba ya escrito y hasta después de su publicación en La invasión de 2006, escribió y publicó varias reflexiones sobre las cuestiones con las cuales allí se enfrenta, a partir de Pavese y de su obra, pasando por la narración como ficción paranoica, la ausencia de la mujer como detonante de la narración, la forma diarística, entre otras. Con el doble efecto de preparar a sus lectores para la lectura del texto, permitiéndoles colocarlo en su obra ya publicada, y de hacerla más movediza, apuntan a la necesidad del escritor pero también a la del lector escrupuloso, de volver a los textos del pasado para recolocarlos otra vez en el presente.

En esta línea se han de considerar algunos artículos sobre Pavese, una selección de cartas del escritor italiano titulada "Cesare Pavese. «Las cartas del amor siempre imposible»", publicada por la revista Crisis y cuyas traducciones están revisadas por el mismo Piglia, la antología Cuentos policiales de la serie negra publicada en 1969, las muchas intervenciones teóricas y críticas sobre el cuento, colecciones de ensayos y entrevistas como Crítica y ficción, y también las reflexiones presentes en otras obras de ficción, a partir de Nombre falso, nouvelle en la cual estalla la hibridación entre crítica y ficción insinuada en "Un pez en el hielo", pasando por Respiración Artificial donde los mecanismos de la novela detectivesca 
son enfatizados y puestos al servicio de reflexiones históricas y literarias, para llegar a $L a$ ciudad ausente donde se desarrolla el tema de la ausencia de la mujer como motor de la producción literaria, cada texto impacta con todos los otros creando un conjunto en el que cada parte justifica las demás, poniéndolas en perspectiva. En fin, también está la publicación de Los diarios de Emilio Renzi que no solo "exhiben el proceso de construcción de un sujeto literario, sin dejar de lado ninguno de sus avatares" (Mesa Gancedo, 2019: 1), sino que, desde el punto extremo de la vida de Piglia, reordenan ulteriormente todos los textos precedentes, ofreciendo al lector una especie de manual para reconstruir una obra literaria a posteriori. Resulta así evidente que

[...] la obra de Piglia es híper-literaria, y ése es el primer desafío que tiende al lector: sus libros interrogan tanto los discursos narrativos como ensayísticos y trabajan con dimensiones autoreflexivas, meta-literarias y teóricas, pero sin dejar de ejercer una mirada política que cruza todos sus referentes. Una discusión constante acerca de la literatura se abre paso, de manera explícita o secreta, en esas páginas en las que proliferan las remisiones de un género o de un discurso a otro y en las que la marca del escritor suele confundirse con la mirada de un lector acérrimo (Orecchia Havas, 2019b: 2).

En este mismo contexto se justifican operaciones como las reediciones de libros, la reescritura de textos, el desplazamiento de los mismos de un libro a otro y la postergación de la publicación de textos, como es el caso de "Un pez en el hielo".

Bajo todo este entramado de textos, formas y temas, parece evidente que subyazca y actúe constantemente en la obra de Piglia un asunto que se configura como una verdadera obsesión, o sea, la total entrega del escritor a una única pasión, la literatura, por la cual decidió apostarlo todo ya desde su juventud, conformando su vida cotidiana (familiar, sentimental, profesional) a esa pasión, así como lo repite varias veces su alter ego en Los diarios de Emilio Renzi, y como lo explica Fabio Esposito en su artículo sobre la labor editorial de Piglia:

[...] ser escritor es, para Piglia, llevar una vida de escritor, que implica tener tiempo disponible para leer y escribir, pero también ganar un espacio. Conseguir un sitio de trabajo: escritorios, bibliotecas, bares; obtener un lugar en los espacios de sociabilidad: tertulias, revistas culturales, librerías, editoriales. En los comienzos, ese espacio literario está articulado por la industria editorial. La vida literaria es posible porque puede ser sustentada mediante el oficio de escritor, que abarca también la labor editorial. Así, las colaboraciones en revistas literarias, las antologías, las traducciones, la dirección de colecciones no están alejadas del contrato para publicar su primer libro de cuentos. Por el contrario, son modos de vivir la literatura (2018: 131).

Este tema de fondo, presente en todos los escritos de Piglia, es el motor oculto de "Un pez en el hielo", un cuento que habla justamente de la entrada en el mundo literario y de la elección definitiva de entregarse totalmente a esa pasión. Para desarrollar esta cuestión, Piglia pone a Emilio Renzi frente al espejo, donde está reflejada también la imagen de otro escritor, Pavese, y se sirve del mecanismo de los desdoblamientos, complicándolo fuertemente (los cuadernos de tapas negras de Emilio Renzi en el cuento son el doble del diario de Pavese, pero también del diario del mismo Ricardo Piglia, así como de Los diarios de Emilio Renzi, donde uno podría imaginar poder leer las mismas frases que Renzi escribe en el cuento), para identificar a su protagonista con el escritor italiano, otro escritor que se había entregado a la pasión literaria y que había registrado esta entrega en su diario, El oficio de vivir. 
Merece entonces la pena profundizar en la relación que Piglia mantuvo con Pavese para ponerla en relación con "Un pez en el hielo" en los años en que el cuento nació, se desarrolló y fue cambiando hasta su tardía publicación, operación posible gracias a las indicaciones que el escritor argentino ha dejado en el texto del cuento, a los textos que publicó sobre Pavese y su obra, y además, a las informaciones ofrecidas en Los diarios de Emilio Renzi.

En el primer tomo de Los diarios, titulado Años de formación, la primera referencia a Pavese, del 28 de junio de 1960, surge como recuerdo de Renzi de una conferencia de Attilio Dabini. Piglia se apresta a individuar la importancia del escritor italiano en la presencia peculiar de un diario: "Recuerdo la conferencia de Attilio Dabini sobre Pavese. Fue importante para mí porque escribe un diario titulado El oficio de vivir. Se mató pero antes dejó el libro preparado para su edición" (2015: 81). Pero ya en el texto de apertura de la obra, titulado significativamente "En el umbral", la figura de Pavese y el libro El oficio de vivir aparecen en toda su importancia. Dice Renzi, hablando de los libros que acompañaron su descubrimiento de la literatura:

el libro más antiguo es La peste. Luego hay una serie de dos: El oficio de vivir de Pavese y Stendhal par lui-même. Fueron los primeros que compré, a los que siguieron cientos y cientos. Los he traído y llevado conmigo como un talismán o un fetiche, y los he puesto sobre las paredes de piezas de pensión, departamentos, casas, hoteles, celdas, hospitales. Se puede ver cómo es uno a lo largo del tiempo sólo con hacer un recorrido por los muros de la biblioteca: sobre Pavese escuché una conferencia de Attilio Dabini y compré el libro (porque yo también escribía un diario). (2015: 26).

Como se ve, la figura de Pavese está inmediatamente relacionada con la forma literaria del diario, y enseguida Piglia evidencia el paralelismo entre su diario y El oficio de vivir. Empieza con estas líneas un mecanismo, lento, de desdoblamiento intelectual que seguirá fortaleciéndose, abarcando todos esos temas que, tras haber afectado la vida y las reflexiones existenciales y estéticas de Pavese, interesan ahora a Piglia, quien aprovecha de la experiencia del otro escritor para profundizarlas.

En 1963 el interés hacia Pavese se concretiza en la publicación de un artículo en la revista El Escarabajo de Oro en el que Piglia reconstruye la personalidad del italiano, su trayectoria literaria y existencial, en fin, su suicidio:

[...] no escribir más era, para él, inaguantable; pero dejaba de escribir porqué todo era inaguantable. No resistió. "Como Cortés, me he quemado las naves. No sé si encontraré el tesoro de Moctezuma, pero sé que sobre el altiplano de Tenochtitlan se hacen sacrificios humanos", dijo en su última carta. Y se mató. Su lucidez y su soledad: su suicidio pudoroso. Los hombres como él no se matan por algo o por nada, sino por todo (1963: 18).

Esta reflexión sobre la relación estrecha que vincula la escritura con la muerte, el suicidio, reaparece en la sección central de "Un pez en el hielo", cuando Renzi compara la situación de Pavese con Kafka, hallando diferencias determinantes:

[...] en todo caso Kafka decía que no podía escribir... pero siempre volvía a empezar. En cambio Pavese había ordenado sus papeles, pensaba que en su oficio era un rey. (Kafka, en cambio, se veía a sí mismo como un sirviente). Si Pavese hubiera escrito sobre ese estado se habría salvado... Pero hay que ser Kafka o ser Roberto Arlt. Escritor fracasado. (Un pleonasmo). Pavese entonces había sobrevivido varios días. Cuando tendría que haber 
empezado a escribir, dejó de escribir. Sostenerse en una zona gris. Un pez en el hielo. Soy un muerto aparente. (2006a: 185)

En Los diarios de Emilio Renzi, el diario del 1963, año presentado como clave para los comienzos literarios del escritor, se cierra con un texto, "Los diarios de Cesare Pavese", un ensayo complementario y especular a lo que Piglia había publicado en El Escarabajo de Oro, y donde está reproducida una vez más esta misma idea, acaso con más lucidez, y ofreciendo una clave clara para decodificar el mensaje contenido en "Un pez en el hielo". Escribe Renzi, comentando El oficio de vivir:

[...] relato vacío, relato donde sólo se registra el pensamiento (de la muerte), al mismo tiempo Pavese escribe el diario para postergar el suicidio. En este sentido el trabajo con el doble es, como siempre, un modo de conjurar la muerte. Texto límite, el deseo que lo recorre es el de estar muerto y a la vez poder escribir sobre esa muerte. Ésta es la contradicción que resuelve imaginariamente el mito del doble que se fascina con la idea del suicidio. La última frase del texto, implacable, hace ver que la escritura era su única (última) defensa: "Basta de palabras, un gesto, no escribiré más." En el futuro de ese verbo está la muerte: lo que vendrá cuando ya no se escriba (2015: 146).

Aunque la primera referencia directa a un cuento sobre Pavese en Los diarios de Emilio Renzi se remonta al año 1965 ("escribir la historia de Pavese, ligada a la vida de un pianista de cabaret que toca todas las noches tangos y milongas hasta que, sorpresivamente, una mañana se suicida" [2015: 178]), ya en ese 1963 estaban presentes para Piglia todos los elementos que hallarán lugar en "Un pez en el hielo".

En el texto que precede el diario de ese año, "En el estudio", Piglia nos presenta la situación intelectual del joven Renzi, dividido entre el empeño político y la ambición literaria, entre los desafíos de la literatura, la carrera univeresitaria y la relación con una mujer, Inés:

[...] ya en aquel tiempo lejano yo vivía una doble vida y practicaba la esquizofrenia que ha definido mi actitud ante la realidad. Por un lado, en La Plata llevaba adelante una práctica política, muy teórica, con un grupo de intelectuales avanzados de izquierda y, por otro lado, viajabas todas las semanas a Buenos Aires, donde pasaba dos o tres días frecuentando el mundito literario, cierta bohemia juvenilista, y me reunía con escritores jóvenes en el bar Tortoni todos los viernes [...]. También en aquel tiempo, junto con mis vitas paralelas, encontré un amigo con el que pasé varias pruebas decisivas en esos años de aprendizaje y educación (sentimental). Avanzaba fluidamente en la carrera y al año siguiente, en 1963, conseguí trabajo como ayudante de cátedra en dos materias y empecé, por primera vez, a ganarme la vida y también — tal vez como resultado de tener un trabajo - a vivir con una mujer uruguaya, Inés, lo que he llamado "mi primer matrimonio", aunque por supuesto no nos casamos ni nada parecido, sólo que establecí una relación estable durante varios años con una mujer $(2015: 127,134)$.

Y el diario del '63 acaba, un jueves de diciembre, con una entrada que reitera la situación del joven intelectual que ha movido sus primeros pasos para entrar en el mundo de la literatura:

[...] tal vez deba hacer un resumen de mi situación porque durante varios meses he desatendido estos cuadernos. Por primera vez este año me di a conocer, como quien dice, dejé de ser inédito. En la revista publiqué un ensayo sobre el diario de Pavese y un cuento ("Desagravio") dedicado a mi amigo José Sazbón, el tema es el bombardeo a Plaza de Mayo, mezclado con una historia privada (un hombre mata a una mujer). Esas novedades han sido, en definitiva, la realización, menor quizá, de mis proyectos o mis fantasías que tengo conmigo desde los 
dieciséis años. Este año además empecé a ganarme la vida con las dos cátedras en las que trabajo como ayudante rentado (2015: 141).

Aparte de la referencia al ensayo sobre Pavese y su diario, la impresión que se tiene de la estructura y el contenido de esta parte de Los diarios de Emilio Renzi es que el joven intelectual necesitaba un modelo, una figura en la cual poder reconocer sus esperanzas, sus ambiciones, su perseverancia y también su miedo, su fragilidad. Lo confirma el mismo escritor, apuntando a cierta casualidad en la elección de Pavese como "aliado", y al mismo tiempo reconociendo su figura como una obsesión:

Pavese, un relato. Yo había elegido ir a Italia porque era lo que tenía más a mano, me obsesioné con Pavese, pero podría haber sido cualquier otro, Osamu Dazai, digamos, siempre que estuviera medio vencido, un aliado que me ayudara a actuar. Pero elegí El oficio de vivir y pedí una beca en la Dante Alighieri y pude viajar e instalarme en Turín (Piglia, 2016: 94).

En todo caso la admiración hacia Pavese es totalmente genuina, y Piglia llega a exprimirla, por voz de Renzi, hasta con tonos muy patéticos y volviendo, una vez más, a explicitar ese juego del doble que se instaura entre él y el escritor italiano, y que hallará su síntesis en "Un pez en el hielo”: “¿Fue un modo de posar mi sorpresivo llanto al leer las terribles cartas finales de Pavese? [...] un modo de parecer sensible, digno, llorar por Pavese como si fuera yo mismo" (2016: 79).

Leyendo las entradas del diario dedicadas a Pavese, es fácil darse cuenta de que la admiración de Piglia estaba especialmente dirigida a la estatura ética del escritor italiano en relación con la literatura. Lo que asombró al joven escritor argentino fue, por un lado, la total interpenetración entre la obra de Pavese, en particular El oficio de vivir, y su propia vida, como ya se señalaba en los primeros párrafos de su artículo de 1963: "en el hombre se dan las claves de su obra, y viceversa, en una relación dialéctica y creadora: su lucidez constante, su compromiso político, su responsable y laboriosa comprensión estética, su soledad, su suicidio" (1963: 2); por otro lado, la total y extrema entrega a su pasión literaria, que Renzi, en una entrada del diario de 1968, se impone emular: "aprender del Pavese de 1935, en pleno confinamiento con tres años de destierro por delante, sin noticias de la mujer que amaba, solo, a la intemperie, en su diario escribe sobre poesía, sobre su manera de trabajar, nunca se deja ganar por las «tragedias del alma»" (2016: 76). Estas son las huellas de Pavese que Piglia quiere seguir.

Como ya se ha visto, el mecanismo de desdoblamiento entre Renzi y Pavese se repite en "Un pez en el hielo", replicando también la superposición de hechos vitales, como sucede cuando Renzi hace la cuenta de los años de vida que le quedan basándose en la edad de Pavese a la hora de su suicidio.

Así, Los diarios de Emilio Renzi actúan sobre el relato "Un pez en el hielo" como sobre las otras obras de Piglia: este extenso texto autoficcional "funciona como un protocolo de lectura que el lector necesita para interpretar la obra de Piglia" (Fernández Cobo, 2018: 199). Y en este caso hace posible una lectura más completa y compleja del relato, desvelando la elección del protagonista, alter ego de Piglia, de seguir las huellas de Pavese y entregar su vida a la literatura. Al mismo tiempo, este texto se convierte en una especie de exorcismo, una toma de conciencia y una promesa consigo mismo, y que luego Piglia persiguió hasta sus últimos días: frente a Pavese, que había dejado la escritura para entrar en el mundo sin 
palabras de la muerte voluntaria, Piglia decide continuar a escribir y no solo ha logrado hacer esto, escribiendo hasta los últimos días de su vida, sino que ha conseguido hacer que su escritura sigua actuando como un organismo vivo, que sus textos continúen construyendo un diálogo activo entre sí y con las obras de sus escritores de referencia, entre los cuales Pavese, como se ha podido ver, tiene un lugar central y privilegiado.

De esta manera, un texto como "Un pez en el hielo", en sí bastante lineal y todavía lejos de las experimentaciones, que Piglia desarrollará en sus novelas como Respiración artificial y La ciudad ausente o en nouvelles como Nombre falso, adquiere un espesor y una profundidad particulares, revelando posibilidades aún no exploradas para el género literario del relato breve.

\section{Bibliografía.}

ESPOSITO, Fabio: “Ricardo Piglia, editor”. Badebec VIII/15 (2018): 128-139.

FERNÁNDEZ COBO, Raquel: "Los diarios de Ricardo Piglia: una lectura en busca de la experiencia perdida". Castilla. Estudios de Literatura 8 (2017): 62-97. DOI: https://doi.org/10.24197/cel.8.2017.62-97

GALLEGO CUIÑAS, Ana: "La ficción paranoica de Ricardo Piglia en «Un pez en el hielo»: encrucijada narrativa". Otro Lunes. Revista Hispanoamericana de Cultura 1 (2007), disponible en http://otrolunes.com/archivos/05/html/unos-escriben/unos-escriben-n05a15-p01-2008.html (última consulta: 30/08/2019).

MESA GANCEDO, Daniel: "La némesis literaria de Emilio Renzi en sus Diarios (de Ricardo Piglia)". Cuadernos Lírico, Hors-série (2019), disponible en http://journals.openedition.org/lirico/7934 (última consulta: 30/08/2019). DOI: https://doi.org/10.4000/lirico.7934

--- (2006): "Una propuesta de lectura en el origen de la obra de Ricardo Piglia". En Daniel Mesa Gancedo (coord.): Ricardo Piglia. La escritura y el arte nuevo de la sospecha. Sevilla: Universidad de Sevilla, Colección Escritores del Cono Sur, 163-226.

ORECCHIA HAVAS, Teresa: "El último viaje de Orfeo: Los diarios de Emilio Renzi". Cuadernos Lírico, Hors-série (2019a), disponible en http://journals.openedition.org/lirico/7921 (última consulta: 30/08/2019). DOI: https://doi.org/10.4000/lirico.7921

---: "Lenguajes, difracciones, nostalgias". Cuadernos Lírico, Hors-série (2019b), disponible en http://journals.openedition.org/lirico/7878 (última consulta: 30/08/2019). DOI: https://doi.org/10.4000/lirico.7878

PAVESE, Cesare (1998): El oficio de vivir. 1935-1950. Barcelona: Planeta.

PIGLIA, Ricardo: “Cesare Pavese”. El Escarabajo de Oro 17 (1963): 2 y 18.

--- (2001): Crítica y ficción. Barcelona: Anagrama.

--- (2006a): La invasión. Barcelona: Anagrama.

--- (2006b): Formas breves. Barcelona: Anagrama.

--- (2015): Los diarios de Emilio Renzi. Años de formación. Barcelona: Anagrama.

--- (2016): Los diarios de Emilio Renzi. Los años felices. Barcelona: Anagrama. 
--- (2018): “Prólogo". En Ernest Hemingway: En nuestros tiempos. Buenos Aires: Lumen, 38.

ROMERO, Julia Graciela: "Ricardo Piglia: una poética de la reescritura". Orbis Tertius XV/6 (2010): 102-109.

(C) Mirko Olivati

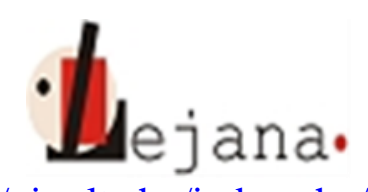

http://ojs.elte.hu/index.php/lejana

Universidad Eötvös Loránd, Departamento de Español, 1088 Budapest, Múzeum krt. 4/C 